\title{
BMJ Open How do ED patients with criminal justice contact compare with other ED users? A retrospective analysis of ED visits in California
}

\author{
Shannon McConville, ${ }^{1}$ Alyssa C Mooney, ${ }^{2}$ Brie A Williams, ${ }^{3}$ Renee Y Hsia $^{4}$
}

To cite: McConville $S$, Mooney AC, Williams BA, et al. How do ED patients with criminal justice contact compare with other ED users? $A$ retrospective analysis of $E D$ visits in California. BMJ Open 2018;8:e020897. doi:10.1136/ bmjopen-2017-020897

- Prepublication history and additional material for this paper are available online. To view these files, please visit the journal online (http://dx.doi. org/10.1136/bmjopen-2017020897).

Received 30 November 2017 Revised 20 March 2018 Accepted 1 May 2018

Check for updates

${ }^{1}$ Public Policy Institute of California, San Francisco, California, USA

${ }^{2}$ Department of Epidemiology and Biostatistics, University of California, San Francisco, San Francisco, California, USA ${ }^{3}$ School of Medicine, University of California, San Francisco, San Francisco, California, USA ${ }^{4}$ Department of Emergency Medicine, Philip R. Lee Institute for Health Policy Studies,

University of California, San

Francisco, San Francisco, California, USA

Correspondence to

Dr Renee Y Hsia;

renee.hsia@emergency.ucsf.edu

\section{ABSTRACT}

Objective To assess the patterns of emergency department (ED) utilisation among those with and without criminal justice contact in California in 2014, comparing variation in ED use, visit frequency, diagnoses and insurance coverage.

Design Retrospective, cross-sectional study.

Setting Analyses included ED visits to all licensed hospitals in California using statewide data on all ED encounters in 2014.

Participants Study participants included 3757870 nonelderly adult ED patients who made at least one ED visit in 2014.

Primary and secondary outcome measures We assessed the patterns and characteristics of ED visits among those with criminal justice contact-patients who were either admitted to or discharged from the ED by a correctional institution-with patients who did not have criminal justice contact recorded during an ED visit. Results ED patients with criminal justice contact had higher proportions of frequent ED users $(27.2 \%$ vs $9.4 \%$ ), were at higher risk of an ED visit resulting in hospitalisation ( $26.6 \%$ vs $15.2 \%$ ) and had higher prevalence of mental health conditions (52.8\% vs $30.4 \%)$ compared with patients with no criminal justice contact recorded during an ED visit. Of the top 10, four primary diagnoses among patients with criminal justice contact were related to behavioural health conditions, accounting for $19.0 \%$ of all primary diagnoses in this population. In contrast, behavioural health conditions were absent from the top 10 primary diagnoses in ED patients with no observed criminal justice contact. Despite a high burden of disease, a lack of health insurance coverage was more common among those with criminal justice contact than those without ( $41.3 \%$ vs $14.1 \%)$.

Conclusions Given that a large proportion of ED patients with criminal justice contact are frequent users with considerable mental health conditions, current efforts in California's Medicaid programme to identify individuals in need of coordinated services could reduce costly ED utilisation among this group.

\section{INTRODUCTION}

In California, criminal justice reforms implemented in recent years have resulted in a reduction in the number of people incarcerated in

\section{Strengths and limitations of this study}

- To our knowledge, this is the first study that examines emergency department (ED) visits among patients with criminal justice contact in California since implementation of the state's Medicaid expansion under the Affordable Care Act which greatly increased access to insurance coverage for this group.

- It is also the first to compare ED visits made while justice-involved individuals are in custody versus those made while they are in the community.

- Our use of routinely collected hospital data to profile frequent ED users with criminal justice contact illustrates a potential tool that for administrative data could provide to identify and target high-need individuals that access multiple public systems.

- We were only able to examine criminal justice contact tied to a hospital encounter which may not be representative of the overall criminal justice population.

- The frequency of criminal justice contact and the number of patients with criminal justice contact may be underestimated due to missing patient identifiers among this population which allow us to link ED visits across patients.

the state. Public safety realignment, enacted in 2011 in response to a court-ordered mandate to reduce the state prison population, shifted responsibility for 'lower-level felons' from state prisons to local jails. A few years later, Proposition 47 was approved by voters and reclassified certain drug and property crimes from felonies to misdemeanours. ${ }^{1}$ These policy changes have shifted focus as well as funding resources towards alternatives to incarceration and efforts to improve transitions back into the community. ${ }^{1}$ As increasing numbers of people return home from correctional settings, there is a growing urgency to understand their healthcare needs to improve health and re-entry outcomes and to deploy an efficient use of healthcare resources. 
Available data suggest that $80 \%$ of incarcerated men and $90 \%$ of women have health conditions requiring treatment or management, ${ }^{2}$ and the high prevalence of behavioural health conditions including serious mental illness and substance use disorders among criminal justice-involved populations contributes to recidivism. ${ }^{3}$ Yet, a minority of prisoners receives treatment for behavioural health or medical conditions while incarcerated, and treatment further declines on release. ${ }^{2-8}$ Many challenges are encountered when accessing healthcare postrelease, including lack of insurance and medication supplies, high costs of care, long wait times for appointments and difficulties navigating siloed medical, behavioural health and social services. ${ }^{27}$

While these difficulties likely contribute to high rates of emergency department (ED) utilisation among the justice involved, research on this population's acute care usage patterns is primarily limited to small samples, self-report data and short timeframes. Institutionalised individuals are excluded from most population surveys, ${ }^{9}$ and informational gaps are compounded by funding limitations, with just $0.1 \%$ of funded National Institutes of Health grants focusing on criminal justice health research. ${ }^{10}$ Despite these challenges, studies that followed cohorts in the first year postrelease found high proportions of ED use, ranging from $25 \%$ to $56 \%$ after release from prison, ${ }^{11} 12$ and $65 \%$ of individuals with HIV after release from jail. ${ }^{13}$ National studies found individuals with past-year criminal justice involvement were more likely than the overall population to have used the ED or been hospitalised in the last year. ${ }^{1415}$ Other studies linked administrative data from correctional departments, hospitals and Medicare claims to show higher rates of ED visits and hospitalisations among those released from correctional institutions, particularly for mental health, substance use disorders and other ambulatory care sensitive conditions. ${ }^{1617}$

Few studies have examined acute care utilisation among justice-involved individuals in more recent years after the Affordable Care Act (ACA) provided opportunities for health coverage among the justice involved in states that chose to expand their Medicaid programmes. ${ }^{15}$ And no studies have focused on California-where major criminal justice reforms, coupled with state legislation, have created both opportunities and incentives for correctional institutions, including local jails and the state's prison system, to connect justice-involved individuals with insurance coverage ${ }^{18}$ Still, despite these policy changes and the dramatic reduction in incarceration in California, rearrest and reconviction rates have remained largely unchanged. ${ }^{19}$ And given the substantial burden that correctional healthcare places on state budgets, especially in California, which has the highest per-capita spending on inmate healthcare in the nation, it is crucial to understand the acute care needs of those involved with criminal justice systems. ${ }^{20}$

In order to reduce recidivism, management of behavioural health conditions that often lead to incarceration must be improved. ${ }^{21}$ The possibility for achieving this has been greatly bolstered under the ACA, which has been linked to increased insurance coverage for the justice involved, ${ }^{22}$ and provides a much needed funding source to correctional agencies and safety net providers who serve this population. Characterising diagnostic profiles and the patterns and drivers of ED use in the year after California implemented its Medicaid expansion provides important baseline information that can inform strategies to better meet the continuing healthcare needs of this population-both while they are in custody and in the community-and could contribute to reduced acute care utilisation and recidivism rates. Additionally, no studies to our knowledge have looked specifically at differences in ED visits that have direct contact with the criminal justice system compared with those that occur while justice-involved individuals are not incarcerated and in their community.

In this study, we leveraged statewide data on all ED encounters in California hospitals to assess the patterns of ED utilisation among patients who had criminal justice contact recorded during an ED visit in 2014. We compared patient characteristics including demographics, health conditions, and coverage sources and examined variations in frequency of ED use among those with and without justice-involved ED visits. We also examined primary diagnoses and health insurance coverage across visits with different types of criminal justice contact in order to better understand how health conditions are being managed in the communities to which correctional populations are returning.

\section{METHODS}

\section{Study design and data source}

We performed a retrospective analysis of ED visits in 2014 using non-public data from the California Office of Statewide Health Planning and Development (OSHPD). All licensed hospitals in California except those federally operated are required to report inpatient admissions and ED discharge data to OSHPD. The ED discharge dataset does not include ED visits that resulted in a hospitalisation; those visits are captured using the patient discharge dataset, which indicates whether a patient was admitted to the hospital from the ED. Using patient-level identifiers (constructed from an encrypted nine-digit alphanumeric identifier and deidentified by OSHPD), we constructed a dataset of all individuals with at least one ED visit in 2014 and linked multiple visits to patients. We successfully linked $88 \%$ of all ED discharge records, although visits that had criminal justice contact had a linkage rate of $70 \%$.

\section{Participants}

We included all adult patients, age 18-64, with any ED visit in a California hospital during the study period. We focused on non-elderly adults as they were the group most impacted by the coverage expansions under the 
ACA. We identified individuals with any direct criminal justice contact during an ED visit over the course of the year based on codes for admission source and disposition. These codes indicate whether patients were admitted from a prison or jail (available only for ED visits that resulted in an inpatient admission), or discharged to a prison or jail after an ED or inpatient visit (available for all ED visits). All patients with at least one ED visit with direct criminal justice contact are coded as having criminal justice involvement during the year. Our ability to link visits across patients allows us to observe ED use while individuals who had a recent ED visit with criminal justice contact were in the community.

\section{Patient involvement}

Patients were not involved in the development of the research question, outcome measures or study design. We did not actively recruit patients for this study, and the results will not be disseminated to the study participants as we used unidentified data and have no way of contacting the patients.

\section{Variables}

\section{Frequent ED use}

There is no standard for what constitutes a 'frequent ED user' ${ }^{23}$ Definitions range from 2 to 12 visits per year, though the most commonly used threshold is four or more annual ED visits. ${ }^{24}$ We chose to examine frequency of ED use based on the following ordinal categories: 1 visit, 2-3 visits, 4-6 visits, 7-10 visits and more than 10 visits. Our analysis of frequent users relies on the most common definition of four or more annual ED visits.

\section{Diagnoses}

We examined health conditions using diagnostic information from all hospital encounters in 2014. Principal diagnosis and up to 24 additional diagnoses are recorded by hospitals using Institutional Classification of Disease, Ninth Revision, Clinical Modification (ICD-9-CM) codes. We grouped all ICD-9-CM codes into clinically meaningful categories using the Agency for Healthcare Research and Quality's Clinical Classifications Software. We used all diagnoses reported across any available patient discharge records, including inpatient visits, to construct our measures of health conditions. We also examined primary diagnoses, which for outpatient ED visits indicate the main cause for the visit and for ED visits that resulted in an inpatient admission indicate the main cause for the entire episode of care.

\section{Patient characteristics}

Patient characteristics included age, gender, race/ ethnicity, preferred language and primary insurance coverage. Race and ethnicity were self-reported by patients. Primary coverage source was defined based on the payer reported for the largest share of a patient's ED visits. In the limited cases where shares were equal among multiple coverage sources, we first assigned patients to Medicare, then Medicaid, then uninsured.

\section{Statistical analysis}

We calculated descriptive statistics to compare patient demographics, ED use, health conditions, primary diagnoses and visit frequencies among patients with and without criminal justice contact recorded during any ED visit in 2014. We performed bivariate analyses using t-tests and $\chi^{2}$ tests. Analyses were conducted in SAS V.9.4 software.

\section{RESULTS}

\section{Patient and ED visit load}

More than 33000 non-elderly adult ED patients had direct criminal justice contact during an ED visit in 2014 out of a total of 3757870 adult patients who made at least one ED visit during the year (table 1). Although they represented only $0.9 \%$ of all ED patients in California, patients with criminal justice contact accounted for $2.6 \%$ of all frequent ED users (four or more annual ED visits) and $5.6 \%$ of all heavy ED users (more than 10 annual ED visits) in the state. More than a quarter $(27.2 \%)$ of justice-involved patients were classified as frequent ED users, and made $71.0 \%$ of ED visits among this group. In comparison, $9.4 \%$ of all non-elderly adult ED patients were frequent $\mathrm{ED}$ users, and made $34.9 \%$ of all ED visits.

Of the more than $131000 \mathrm{ED}$ visits made by patients with any criminal justice contact during the year, 29.7\% had direct criminal justice contact coded for the visit. The remaining $70.3 \%$ of ED usage by this group occurred while individuals were back in the community. Among frequent ED users (4+ visitsannually) with a justice-involved visit, $86.1 \%$ of $\mathrm{ED}$ visits were made while they were in the community and not in the custody of law enforcement.

\section{Characteristics of ED users with and without criminal justice contact}

Comparison of non-elderly adult ED users with and without criminal justice contact (table 2) reveals distinct profiles. Despite their higher frequency of ED use, justice-involved ED patients were a younger population, and less likely to be female $(22.7 \%$ vs $55.6 \%, \mathrm{p}<0.05)$. They were more likely to be non-Hispanic black $(18.0 \%$ vs $11.7 \%, \mathrm{p}<0.05)$, which could reflect the disproportionate share of African-Americans incarcerated in California and the nation as a whole.

Justice-involved ED patients also had unique diagnostic profiles, with a higher prevalence of behavioural health conditions relative to ED patients without a justice-involved ED visit during the year. Specifically, ED users with criminal justice contact were approximately five times more likely to have substance use $(33.7 \%$ vs $6.8 \%, \mathrm{p}<0.05)$ or alcohol-related disorder (25.1\% vs $5.2 \%, \mathrm{p}<0.05)$. Mental health conditions were diagnosed in $52.8 \%$ of ED users with criminal justice contacts, compared with $30.4 \%$ of those without $(\mathrm{p}<0.05)$. Schizophrenia was more common in patients with criminal justice contact $(12.4 \%$ vs $2.3 \%, \mathrm{p}<0.05)$, and represented a far higher 
Table 1 Frequency of ED visits for patients aged 18-64 by criminal justice contact in California, 2014

\begin{tabular}{|c|c|c|c|c|c|c|c|}
\hline & \multicolumn{5}{|c|}{ No of total annual ED visits } & \multirow[b]{2}{*}{ Total } & \multirow{2}{*}{$\begin{array}{l}\text { Frequent } \\
\text { users (4+) }\end{array}$} \\
\hline & 1 & 2-3 & 4-6 & $7-10$ & $10+$ & & \\
\hline \multicolumn{8}{|l|}{ All adult ED patients } \\
\hline$\%$ patients & $65.5 \%$ & $25.1 \%$ & $6.5 \%$ & $1.8 \%$ & $1.1 \%$ & $100.0 \%$ & $9.4 \%$ \\
\hline Total ED visits (N) & 2460890 & 2153072 & 1140640 & 551671 & 780513 & 7086786 & 2472824 \\
\hline \multicolumn{8}{|l|}{ ED patients with criminal justice contact* } \\
\hline Total ED patients $(\mathrm{N})$ & 14374 & 10020 & 4832 & 2013 & 2255 & 33494 & 9100 \\
\hline$\%$ patients & $42.9 \%$ & $29.9 \%$ & $14.4 \%$ & $6.0 \%$ & $6.7 \%$ & $100.0 \%$ & $27.2 \%$ \\
\hline Total ED visits $(\mathrm{N})$ & 14374 & 23658 & 22954 & 16468 & 53700 & 131154 & 93122 \\
\hline \% visits & $11.0 \%$ & $18.0 \%$ & $17.5 \%$ & $12.6 \%$ & $40.9 \%$ & $100.0 \%$ & $71.0 \%$ \\
\hline $\begin{array}{l}\% \text { of all ED patients with criminal justice } \\
\text { contact }\end{array}$ & $0.6 \%$ & $1.1 \%$ & $2.0 \%$ & $2.9 \%$ & $5.6 \%$ & $0.9 \%$ & $2.6 \%$ \\
\hline
\end{tabular}

* Criminal justice contact is defined as having at least one ED visit during the year that had an admission source coded as jail or prison or had a disposition coded as discharged to jail or prison.

ED, emergency department.

proportion of their mental health diagnoses. Among ED users with any mental health diagnosis, schizophrenia was diagnosed in nearly a quarter $(23.5 \%)$ of ED users with criminal justice contact, as compared with $7.6 \%$ of those without.

Justice-involved ED patients also had much higher proportions of infectious diseases compared with those without criminal justice contact. The prevalence of HIV and hepatitis $(0.9 \%$ and $7.2 \%$, respectively) was substantially higher than in users without criminal justice contact $(0.3 \%$ and $1.6 \%$, respectively, $\mathrm{p}<0.05$ for both comparisons). Chronic conditions such as hypertension and heart disease were slightly higher in patients with criminal justice contacts $(21.9 \%$ vs $19.9 \%$ and $12.9 \%$ vs $10.0 \%$, both $\mathrm{p}<0.05)$, despite their younger age distribution. ED users with criminal justice contact also had higher shares of an inpatient hospitalisation $(12.6 \%$ vs $8.3 \%, \mathrm{p}<0.05)$ and an ED visit resulting in admission $(26.6 \%$ vs $15.2 \%)$ in the past year compared with those without criminal justice contact.

While similar proportions of each population were covered by Medicaid (33.9\% of those with criminal justice contact, and $31.9 \%$ ), being uninsured at most or all ED visits occurred in $41.3 \%$ of patients with criminal justice contact, as compared with only $14.1 \%$ of those with no such contacts $(\mathrm{p}<0.05)$.

\section{Top diagnoses of ED visits with and without criminal justice}

\section{contact}

Of the top 10, four primary diagnoses of ED visits made by patients with criminal justice contact included behavioural health conditions (alcohol-related disorders, schizophrenia/other psychotic disorders, substance-related disorders and mood disorders), the sum of which accounted for nearly one in five $(19.0 \%)$ of all primary reasons for ED visits made by this population (table 3 ). In contrast, behavioural health conditions were absent from the top 10 diagnoses in patients with no criminal justice contact during the year which were driven by physical pains such as abdominal pain, sprains and strains, chest pain and back problems.

Further examination of primary diagnoses across ED visits with direct criminal justice contact compared with those that occurred when the individual was in the community reveals additional insights (online supplementary table 1$)$. Nearly a quarter (22.4\%) of ED visits in which the patient was discharged to a jail or prison were for a medical examination or evaluation, likely driven by policies among criminal justice agencies to assess individuals before incarceration. The top diagnosis for ED visits where the source of admission was jail or prison was schizophrenia, pointing to the challenges of criminal justice institutions to manage inmates with severe mental health conditions. ED visits that occurred while justice-involved individuals were in the community again showed several behavioural health conditions topping the list of diagnoses, with alcohol-related visits comprising $10.9 \%$, followed by schizophrenia, which accounted for another $4.8 \%$ of primary diagnoses.

\section{DISCUSSION}

ED patients with a history of criminal justice involvement during the year had far higher shares of frequent ED use 
Table 2 Patient characteristics for non-elderly adult ED users with and without criminal justice contact in California, 2014

ED patients with criminal justice contact $(n=33494)$
ED patients with no criminal justice contact $(n=3724376)$

$P$ values

Type of criminal justice contact

$\begin{array}{cll}\text { At least one admission from jail/prison } & 11.3 \% & \text { N/A } \\ \text { At least one discharge to jail/prison } & 90.5 \% & \text { N/A } \\ \text { At least one ED visit in community } & 53.8 \% & \text { N/A } \\ \text { ge at admission (mean) } & 37.2 & 40.0\end{array}$

N/A

/A

40.0

$<0.05$

Age categories

\begin{tabular}{|c|c|c|c|}
\hline Age 18-34 & $48.0 \%$ & $40.6 \%$ & $<0.05$ \\
\hline Age $35-44$ & $21.3 \%$ & $18.8 \%$ & $<0.05$ \\
\hline Age $45-54$ & $20.5 \%$ & $21.0 \%$ & $<0.05$ \\
\hline Age 55-64 & $10.2 \%$ & $19.6 \%$ & $<0.05$ \\
\hline \multicolumn{4}{|l|}{ iender } \\
\hline Female & $22.7 \%$ & $55.6 \%$ & $<0.05$ \\
\hline \multicolumn{4}{|l|}{ lace/ethnicity } \\
\hline Non-Hispanic white & $45.3 \%$ & $43.3 \%$ & $<0.05$ \\
\hline Non-Hispanic black & $18.0 \%$ & $11.7 \%$ & $<0.05$ \\
\hline Hispanic & $31.0 \%$ & $33.2 \%$ & $<0.05$ \\
\hline Non-Hispanic Asian & $1.9 \%$ & $6.3 \%$ & $<0.05$ \\
\hline Non-Hispanic other race & $0.8 \%$ & $0.6 \%$ & $<0.05$ \\
\hline Race missing & $3.0 \%$ & $5.1 \%$ & $<0.05$ \\
\hline
\end{tabular}

Primary coverage source

\begin{tabular}{|c|c|c|c|}
\hline Medicare & $5.9 \%$ & $7.3 \%$ & $<0.05$ \\
\hline Medicaid & $33.9 \%$ & $31.9 \%$ & $<0.05$ \\
\hline Uninsured & $41.3 \%$ & $14.1 \%$ & $<0.05$ \\
\hline Inpatient hospitalisation & $12.6 \%$ & $8.3 \%$ & $<0.05$ \\
\hline ED visit resulting in admission & $26.6 \%$ & $15.2 \%$ & $<0.05$ \\
\hline Mental health & $52.8 \%$ & $30.4 \%$ & $<0.05$ \\
\hline Schizophrenia & $12.4 \%$ & $2.3 \%$ & $<0.05$ \\
\hline Alcohol & $25.1 \%$ & $5.2 \%$ & $<0.05$ \\
\hline Substance use & $33.7 \%$ & $6.8 \%$ & $<0.05$ \\
\hline Asthma & $9.3 \%$ & $7.7 \%$ & $<0.05$ \\
\hline COPD & $5.1 \%$ & $3.8 \%$ & $<0.05$ \\
\hline Cancer & $2.1 \%$ & $3.2 \%$ & $<0.05$ \\
\hline HIV & $0.9 \%$ & $0.3 \%$ & $<0.05$ \\
\hline Hepatitis & $7.2 \%$ & $1.6 \%$ & $<0.05$ \\
\hline
\end{tabular}

Criminal justice contact is defined as having at least one ED visit during the year that had an admission source coded as jail or prison or had a disposition coded as discharged to jail or prison. All $\mathrm{P}$ values are based on two-tailed t-test of the difference in means across the two groups. ED, emergency department. COPD, chronic obstructive pulmonary disease.

compared with other adult ED users, and were at higher risk of inpatient admissions. Given that only $6.7 \%$ of ED patients with criminal justice contact comprised $40.9 \%$ of all ED visits by this group, identifying individuals in need of more coordinated health and social service provision could reduce a portion of this costly health service utilisation. $^{25}$ Our results corroborate previous research that demonstrates high rates of acute care use among criminal justice-involved populations, particularly for mental health and substance use disorders, ${ }^{12-14161726}$ and 


\begin{tabular}{|c|c|c|c|}
\hline Criminal justice contacts $(n=131154)$ & $\%$ & No criminal justice contacts ( $n=6955$ 632) & $\%$ \\
\hline Alcohol-related disorders & 9.2 & Abdominal pain & 5.7 \\
\hline Medical examination/evaluation & 6.8 & Sprains and strains & 4.3 \\
\hline Superficial injury; contusion & 4.7 & Non-specific chest pain & 3.9 \\
\hline Schizophrenia/other psychotic disorders & 4.2 & Spondylosis; intervertebral disc disorders; other back problems & 3.5 \\
\hline Non-specific chest pain & 3.5 & Superficial injury; contusion & 3.2 \\
\hline Skin/tissue infections & 3.4 & Headache; including migraine & 3.1 \\
\hline Abdominal pain & 3.0 & Skin/tissue infections & 3.0 \\
\hline Substance-related disorders & 2.9 & Urinary tract infections & 2.7 \\
\hline Injuries/conditions due to external causes & 2.8 & Other upper respiratory infections & 2.5 \\
\hline Mood disorders & 2.7 & Open wounds of extremities & 2.3 \\
\hline All other diagnoses & 56.9 & All other diagnoses & 65.8 \\
\hline
\end{tabular}

Criminal justice contact is defined as having at least one ED visit during the year that had an admission source coded as jail or prison or had a disposition coded as discharged to jail or prison.

ED, emergency department.

provides new information about the characteristics of ED visits with and without direct criminal justice contact.

Focusing on addressing the uniquely high burden of behavioural health conditions in patients with a history of incarceration would be particularly beneficial. Among ED users with criminal justice contacts, the high prevalence of mental health conditions $(52.8 \%)$, particularly schizophrenia (12.4\%) and alcohol-related $(25.1 \%)$ and substance use disorders $(33.7 \%)$, likely contributes to their cycling between EDs and the criminal justice system. These findings appear to reflect the product of criminalising substance use disorders and drastically reducing psychiatric beds in the mental health system, which has led to an $80 \%$ prevalence of mental health and substance use disorders in jail and prison populations. ${ }^{527}$ Previous research has found that only $22.6 \%$ of inmates with mental health disorders in jails and $22.3 \%$ in state prisons receive any form of mental health treatment in the year before arrest. ${ }^{5}$ The frequent contacts across hospital and correctional systems reflected in our data further suggests these conditions are inadequately managed, and that there may be opportunities to better use contacts with either correctional institutions or EDs to connect individuals to needed behavioural health services to interrupt this cycle of acute care utilisation and recidivism.

Our examination of demographic profiles of ED users with criminal justice contact indicated whites and females were vastly over-represented among justice-involved ED patients, as compared with the total incarcerated population. In California, whites comprised $18.1 \%$ of inmates in jails and $22.2 \%$ in prisons, ${ }^{28}{ }^{29}$ but represented $45.3 \%$ of ED patients with criminal justice contacts. A very small proportion of the correctional population in California is female $-4.4 \%$ in prisons and $13.3 \%$ in jails ${ }^{28}{ }^{29-}$ while females made up nearly one-quarter $(22.7 \%)$ of justice-involved ED patients. While there is evidence of higher disease burden among female jail inmates, ${ }^{30}$ our results indicate differences in race and gender patterning of disease profiles among the justice involved which may signal disparities in access to acute care services both in custody and on release and warrants further research.

Despite a high burden of disease, a lack of health insurance coverage was much more common among those with criminal justice contacts than those without $(41.3 \%$ vs $14.1 \%)$. The ACA has expanded insurance coverage, particularly for mental health and substance use disorders, which could prove salutary for the justice involved in particular if sustained. ${ }^{31-33}$ Other studies have found that the dependent coverage mandate and Medicaid expansion have resulted in declines in uninsurance among justice-involved individuals, but reflect our findings that uninsurance rates remain higher than the general population. ${ }^{22}{ }^{34}$ An increasing number of states, including California, are adopting policies that suspend rather than terminate Medicaid coverage during incarceration, which could reduce gaps in health coverage on release. Jails operating as enrolment sites provide a promising strategy to achieve coverage gains for hard-to-reach populations who are uninsured prior to incarceration. $^{18}$

Though critical, coverage is only the first step in improving health conditions and service utilisation in justice-involved populations. While coverage improved following ACA, evidence is limited and mixed as to whether treatment for behavioural health disorders has improved among the justice involved, ${ }^{22} 34$ and barriers to substance use disorder and other mental health treatment are not limited to insurance. ${ }^{35}$ The geographical distribution of substance use and mental health treatment facilities is highly variable, with lower access in African-American and Latino communities disproportionately impacted by the criminal justice system. ${ }^{7}$ Focusing resources on improving access to behavioural health treatments is imperative to reduce costs, crime and improve population health and social outcomes.

For the services that are available, linkages to community health providers following incarceration are often poor, contributing to high acute care utilisation. ${ }^{2}$ These poor linkages are notable given that this population is at high risk for poor health outcomes due to several factors 
that are commonly reported in this population, including: poor access to medical care before contact with the criminal justice system; low quality medical care received during detainment; mistrust of medical providers; experiences of bias or racism in the doctor-patient relationship and-for some-the criminal justice system itself may have an adverse impact on health including post-traumatic stress disorder and poorly controlled chronic health conditions. ${ }^{36}{ }^{37}$ Fostering the continuity of care between correctional and community health systems will be vital to better manage health conditions in justice-involved populations, reduce the high rate of ED use on release and improve re-entry outcomes. ${ }^{33}{ }^{38}$ Doing so will require increased coordination between corrections and community healthcare settings, particularly information exchange. ${ }^{38}$ An assessment of opportunities for health and criminal justice information exchange identified the potential, with privacy and confidentiality protections in place, for such data linkages to improve health and public safety outcomes and to reduce expenditures across systems. ${ }^{39}$ In addition to improving routine service provision, data linkages would enable more rigorous evaluations of programmes and policies by creating a system for tracking access to services and subsequent changes in health and criminal justice outcomes.

Finally, the routinely collected hospital data we analysed indicate there is considerable potential for ED utilisation to identify frequent users of multiple systems, and to serve as a point of linkage for insurance enrolment and referrals for behavioural healthcare and social services. This is especially true in a post-ACA environment where many of justice-involved individuals are now eligible for Medicaid coverage. A few California counties have developed integrated data systems to identify high users of multiple systems and have used this metric to target individuals for enrolment in Whole Person Carepilot projects, which have been approved by the Centers for Medicare and Medicaid Services and funded through the state's current 1115 Medicaid waiver. ${ }^{40}$ Individuals with criminal justice contact are one prime target population for this intervention, as are the homeless, those with severe mental illness and substance use disorders. Medicaid managed care plans, along with other local partners, are responsible for coordinating care and improving outcomes for this group. It will be essential to monitor and evaluate these programmes and identify successful strategies for service and systems integration that can be expanded to address the profound and urgent need to improve outcomes for the justice-involved population.

\section{Limitations}

First, due to the nature of the hospital discharge data, only criminal justice contact tied to a hospital encounter was observed and may not be representative of the overall criminal justice population. We should note that because we only observe criminal justice contact during an ED visit, it is quite likely that some patients in our comparison group of adults without criminal justice contact may have been incarcerated at some point during the year, but did not have an ED visit while in custody. Second, although California is a very large and diverse state, the heterogeneity of criminal justice systems and the differential implementation of the ACA across states may limit the generalisability of this study. Third, valid patient linkage numbers were more often missing in patients with criminal justice contact, resulting in a lower linkage rate in this group (70\%, as compared with $88 \%$ in those without criminal justice contacts). Thus, the frequency of criminal justice contact and the number of patients with criminal justice contact may be underestimated. This underscores the extent to which patients are contacting both systems and the benefits that coordinated data systems would offer for cross-system collaboration. Furthermore, with fewer visits linked among patients with criminal justice contact, greater disparities in frequent ED use between patients with and without criminal justice contact are probable. Further exploration is needed to understand and reduce missing data in this patient group, and maximise the value of state hospital data for monitoring and addressing the health needs of this population.

\section{Public health implications}

Improving the health of individuals with histories of incarceration can advance several public health goals including reductions in the transmission of communicable disease, declines in racial/ethnic health disparities, increased public safety, and improved health status and outcomes of disadvantaged families and communities. ${ }^{41} 42$ Medicaid coverage expansions under the ACA offer essential supports and funding to do this, but require more coordinated efforts. Our identification and profiles of ED patients with criminal justice contact found many were frequent ED users with uniquely high rates of behavioural health conditions and infectious diseases. High utilisation across multiple public systems and prevalent, poorly managed chronic diseases indicate the need and opportunity for improved collaboration across health and criminal justice systems to reduce recidivism and improve the health of justice-involved individuals and their communities. Recent health and criminal justice policy reforms have increased the possibilities, and the urgency, for more coordinated strategies to meet the health needs of individuals returning home after periods of incarceration.

Acknowledgements The authors thank the California Office of Statewide Health Planning and Development for their assistance in preparing the datasets used in this project.

Contributors All authors contributed to the conception and design of the study, and the interpretation of the data. RYH obtained the data. SM and ACM contributed to the analysis of data and wrote the manuscript. BAW acquired the funding. BAW and RYH provided supervision. All authors critically reviewed and approved the manuscript.

Funding This work was supported by the University of California Office of the President's Multicampus Research Programs and Initiatives.

Disclaimer The funder had no role in the design and conduct of the study; collection, management, analysis and interpretation of the data; preparation, review or approval of the manuscript and decision to submit the manuscript for publication. 
Competing interests None declared.

Patient consent Not required.

Ethics approval The University of California, San Francisco Committee on Human Research approved this study.

Provenance and peer review Not commissioned; externally peer reviewed.

Data sharing statement The data are available through the California Office of Statewide Health Planning and Development.

Open access This is an Open Access article distributed in accordance with the Creative Commons Attribution Non Commercial (CC BY-NC 4.0) license, which permits others to distribute, remix, adapt, build upon this work non-commercially, and license their derivative works on different terms, provided the original work is properly cited and the use is non-commercial. See: http://creativecommons.org/ licenses/by-nc/4.0/

(C) Article author(s) (or their employer(s) unless otherwise stated in the text of the article) 2018. All rights reserved. No commercial use is permitted unless otherwise expressly granted.

\section{REFERENCES}

1. Lofstrom M, Bird M, Martin B. California's historic corrections reforms. San Francisco, CA: Public Policy Institute of California, 2016.

2. Mallik-Kane K, Visher CA. Health and prisoner reentry: how physical, mental and substance abuse conditions shape the process of reintegration. Washington, DC: Urban Institute, 2008.

3. Bollinger LC, Burns UM, Bush C, et al. Behind bars II: substance abuse and America's prison population. New York, NY: The National Center on Addiction and Substance Abuse at Columbia University, 2010.

4. Wilper AP, Woolhandler S, Boyd JW, et al. The health and health care of US prisoners: results of a nationwide survey. Am J Public Health 2009;99:666-72.

5. James DJ, Glaze LE. Mental health problems of prison and jail inmates. Washington, DC: U.S. Department of Justice; Office of Justice Programs; Bureau of Justice Statistics. Special Report NCJ 213600, 2006.

6. Pope LG, Smith TE, Wisdom JP, et al. Transitioning between systems of care: missed opportunities for engaging adults with serious mental illness and criminal justice involvement. Behav Sci Law 2013;31:444-56.

7. Davis LM, Williams MV, Derose KP, et al. Understanding the Public health implications of prisoner reentry in California: state-of-the-state report. Santa Monica, CA: RAND Corporation, 2011.

8. Freudenberg N, Daniels J, Crum M, et al. Coming home from jail: the social and health consequences of community reentry for women, male adolescents, and their families and communities. Am J Public Health 2008;98:S191-S202.

9. Ahalt C, Binswanger IA, Steinman M, et al. Confined to ignorance: the absence of prisoner information from nationally representative health data sets. J Gen Intern Med 2012;27:160-6.

10. Ahalt $\mathrm{C}$, Bolano $\mathrm{M}$, Wang $\mathrm{EA}$, et al. The state of research funding from the National Institutes of Health for criminal justice health research. Ann Intern Med 2015;162:345-52.

11. Wang EA, Hong CS, Shavit S, et al. Engaging individuals recently released from prison into primary care: a randomized trial. $A m \mathrm{~J}$ Public Health 2012;102:e22-9.

12. Meyer JP, Qiu J, Chen NE, et al. Emergency department use by released prisoners with HIV: an observational longitudinal study. PLoS One 2012;7:e42416.

13. Boyd AT, Song DL, Meyer JP, et al. Emergency department use among HIV-infected released jail detainees. J Urban Health 2015;92:108-35.

14. Frank JW, Linder JA, Becker WC, et al. Increased hospital and emergency department utilization by individuals with recent criminal justice involvement: results of a national survey. J Gen Intern Med 2014;29:1226-33.

15. Winkelman TN, Choi H, Davis MM. The Affordable Care Act, Insurance Coverage, and Health Care Utilization of Previously Incarcerated Young Men: 2008-2015. Am J Public Health 2017;107:807-11.

16. Frank JW, Andrews CM, Green TC, et al. Emergency department utilization among recently released prisoners: a retrospective cohort study. BMC Emerg Med 2013;13:16.

17. Wang EA, Wang Y, Krumholz HM. A high risk of hospitalization following release from correctional facilities in Medicare beneficiaries: a retrospective matched cohort study, 2002 to 2010. JAMA Intern Med 2013;173:1621-8.

18. McConville S, Bird M. Expanding health coverage in California: county jails as enrollment sites. San Francisco, CA: Public Policy Institute of California, 2016.

19. Bird M, Grattet R, Nguyen V. Realignment and recidivism in California. San Francisco, CA: Public Policy Institute of California, 2017.

20. Urahn SK, Ettlinger M, Schiff M, et al. State prison health care spending: an examination. The Pew Charitable Trusts and the John D. and Catherine T. Washington, DC: MacArthur Foundation, 2014.

21. Osher FC, D'Amora DA, Plotkin M, et al; Adults with behavioral health needs under correctional supervision: a shared framework for reducing recidivism and promoting recovery. New York, NY: Council of State Governments Justice Center, 2012.

22. Winkelman TN, Kieffer EC, Goold SD, et al. Health Insurance Trends and Access to Behavioral Healthcare Among JusticeInvolved Individuals-United States, 2008-2014. J Gen Intern Med 2016;31:1523-9.

23. Scott J, Strickland AP, Warner K, et al. Frequent callers to and users of emergency medical systems: a systematic review. Emerg Med J 2014;31:684-91.

24. Doupe MB, Palatnick W, Day S, et al. Frequent users of emergency departments: developing standard definitions and defining prominent risk factors. Ann Emerg Med 2012;60:24-32.

25. Vickery KD, Bodurtha P, Winkelman TNA, et al. Cross-Sector Service Use Among High Health Care Utilizers In Minnesota After Medicaid Expansion. Health Aff 2018;37:62-9.

26. Hiller ML, Webster JM, Garrity TF, et al. Prisoners with substance abuse and mental health problems: use of health and health services. Am J Drug Alcohol Abuse 2005;31:1-20.

27. Lamb HR, Weinberger LE. The shift of psychiatric inpatient care from hospitals to jails and prisons. J Am Acad Psychiatry Law 2005;33:529-34.

28. U.S. Department of Justice; Office of Justice Programs; Bureau of Justice Statistics. Annual survey of jails: jail-level data series, 2014 [computer file]. Washington, DC: U.S. Department of Commerce, Bureau of the Census; ICPSR36274-v1, 2014.

29. California Department of Corrections and Rehabilitation. Prison census data as of December 31. Sacramento, California: Department of Corrections and Rehabilitation, 2013. Census1. 2014.

30. Binswanger IA, Merrill JO, Krueger PM, et al. Gender differences in chronic medical, psychiatric, and substance-dependence disorders among jail inmates. Am J Public Health 2010;100:476-82.

31. Regenstein M, Rosenbaum S. What the Affordable Care Act means for people with jail stays. Health Aff 2014;33:448-54.

32. Beronio K, Glied S, Frank R. How the affordable care act and mental health parity and addiction equity act greatly expand coverage of behavioral health care. J Behav Health Serv Res 2014;41:410-28.

33. Rich JD, Chandler R, Williams BA, et al. How health care reform can transform the health of criminal justice-involved individuals. Health Aff 2014;33:462-7.

34. Saloner B, Bandara SN, McGinty EE, et al. Justice-involved adults with substance use disorders: coverage increased but rates of treatment did not in 2014. Health Aff 2016;35:1058-66.

35. Capoccia VA, Grazier KL, Toal C, et al. Massachusetts's experience suggests coverage alone is insufficient to increase addiction disorders treatment. Health Aff 2012;31:1000-8.

36. Jails FN. prisons, and the health of urban populations: a review of the impact of the correctional system on community health. J Urban Health 2001;78:214-35.

37. Travis J, Western B, Redburn FS. The growth of incarceration in the United States: exploring causes and consequences. Washington, DC National Academics Press, 2014.

38. Patel K, Boutwell A, Brockmann BW, et al. Integrating correctional and community health care for formerly incarcerated people who are eligible for Medicaid. Health Aff 2014;33:468-73.

39. Parker S, Mallik-Kane K, Horvath A. Opportunities for information sharing to enhance health and public safety outcomes: a report by the criminal justice and health collaboration project. Ashburn: Criminal Justice and Health Collaboration Project Working Group IJIS Institute, and Urban Institute, 2013.

40. California Department of Health Care Services. Whole person care pilots. 2017 http://www.dhcs.ca.gov/services/Pages/WholePersonC arePilots.aspx (accessed $26 \mathrm{Jul} 2017$ ).

41. Kinner SA, Wang EA. The case for improving the health of exprisoners. Am J Public Health 2014;104:1352-5.

42. DiPietro B, Klingenmaier L. Achieving public health goals through Medicaid expansion: opportunities in criminal justice, homelessness, and behavioral health with the Patient Protection and Affordable Care Act. Am J Public Health 2013;103:e25-9. 